\title{
The Student as Scientist: Secondary Student Research Projects in Astronomy
}

\author{
R. P. Hollow \\ Blue Mountains Grammar School, Private Mail Bag 6, \\ Wentworth Falls, NSW 2782, Australia \\ and \\ Centre for Astronomy, University of Western Sydney Nepean, \\ PO Box 10, Kingswood, NSW 2747, Australia \\ rhollow@bmgs.nsw.edu.au \\ www.bmgs.nsw.edu.au/rhollow/
}

Received 1999 August 17, accepted 2000 May 2

\begin{abstract}
Student research projects are becoming either integral or optional components of Science curricula in several countries. They provide a valuable opportunity for high school students to experience many of the joys and frustrations that make up the intellectual challenge of Science. Astronomy is one branch of Science that lends itself to student projects. Student Research Projects (SRPs) can be individual, group or collaborative between groups in other schools or countries and may involve professional mentors. Use of the Internet and remote access telescopes allow students to undertake challenging research and make worthwhile contributions to professional programs. This paper presents case studies of student projects in optical and radio astronomy from Australian and overseas schools and details both the benefits and problems faced in conducting such projects. Student responses to involvement in projects are discussed. Potential areas for future collaboration and development are highlighted together with the need for more research as to the most effective ways to implement projects and develop student skills.
\end{abstract}

Keywords: astronomy education

\section{Introduction}

For most students Science, as perceived from their involvement in classes in secondary school, involves the transmission of facts to be learnt for an exam, the ability to remember some formulae and plug the right number in to get the correct answer, and the need to perform some short experiments that hopefully produce the result required by the teacher. Many, if not most, students who spend four or six years going through this system become both somewhat naive and disenchanted about the role and process of Science. The traditional teacherled classroom with its emphasis on passive learning and experiments with predictable outcomes does little to foster and develop the innate curiosity and interest with which many of them commence their formal study of Science. One means by which students can develop both an interest in science and an appreciation of what it involves is through conducting scientific research at an appropriate level.

Student Research Projects (SRPs) involve students undertaking a long-term investigation in a scientific manner. Sometimes, the project is an on-going group one in which individual students join and leave the project over time. Perhaps more common, however, is the individual task that requires students to investigate a problem and report their findings, generally in the form of a written and/or verbal report. The task can be predefined or more open-ended, generally being constrained by a time limit imposed within a school or by curriculum requirements. Time spans of one academic year are possible although many projects can be completed in less time. They do, however, require a greater commitment of time than a typical secondary school laboratory exercise.

Most successful SRP models require a structured and guided approach by the teacher. The requirements for each stage of the project should be made clear to students. Regular monitoring of the student's progress is important and allows for feedback and guidance to be given. In most cases, students will not have all the necessary skills to complete the task at the commencement of the project. One of the aims of SRPs, indeed, is to encourage students to identify, acquire and develop relevant skills as and when needed. The inquiry-based approach to Science that underpins the SRP model requires both students and teachers to acknowledge that the teacher does not always know the answer to a specific question or problem. Teachers have to act more as a mentor or facilitator rather than an imparter of knowledge. This is not to deny the need, however, for the teacher to be well versed in the general techniques and skills required for research.

A successful SRP program allows students to undertake real and valid scientific inquiry at an appropriate level. It echoes the process of the graduate research model at a more manageable, concise level. Whilst many students struggle with aspects of the task, most appear to gain benefit from it. One important factor to consider in planning SRPs is that some students are far more capable and determined than generally imagined, hence the best SRP topics should be open-ended enough to allow the dedicated student every opportunity to pursue their project in depth. It would be a mistake to underestimate their potential. 


\section{Why do a Student Research Project?}

Given the relatively recent adoption of SRPs in secondary school science, it is not surprising that quantitative research into its effectiveness and validity is scarce. The comments here are therefore qualitative and anecdotal in nature, reflecting comments from students over 14 years of running a SRP program at Blue Mountains Grammar School. Whilst encouraging, they underlie the need for more detailed educational research in this field.

Why should a student undertake a SRP? There are many answers to this important question.

(1) It is probably the only time in their school careers that students will actually do real science in contrast to standard experiments.

(2) In doing so they will encounter the fact that Science and research is challenging, thought provoking, frustrating, rewarding and fun! The importance of each of these from an educational perspective should not be underrated.

(3) Given the time and effort required to produce a report on their research, students often have a strong sense of pride and ownership in their work.

(4) Successful completion requires both commitment and determination. Students must also apply organisational techniques to manage the information. All these attributes help in subsequent study and endeavours.

(5) Students undertaking a SRP are likely to develop a more positive and realistic view of Science.

Research projects can be undertaken in any scientific discipline but some disciplines lend themselves more readily to investigations by school students. Astronomy is one of these (Lockwood 1992). It remains an area where amateurs still make a worthwhile contribution to the professional community (e.g. in variable star work and the discovery of comets) and some meaningful data can be obtained with a minimum of equipment. Projects can also be scalable and readily adapted to the available resources. The advent of remote access or robotic telescopes together with the internet and appropriate software allows students to obtain and analyse real astronomical data. Examples of such projects are outlined later. The use of remote telescopes may help overcome one of the problems traditionally facing the implementation of astronomy projects in schools-the need for night-time observing sessions.

\section{National Schemes and Competitions}

There are several schemes that seek to foster student research. Two of these are administered through CSIRO.
CREST Awards. These awards encourage CREativity through Science and Technology ${ }^{*}$ and are generally run through a coordinating teacher at participating schools. There are three award levels, Bronze, Silver and Gold, each having progressively greater requirements. The structure of the scheme encourages students to plan and work through their investigations in an organised manner, achieving goals on the way.

CSIRO Student Research Scheme. This scheme ${ }^{\dagger}$ aims to link senior school students with active researchers at a range of institutions around Australia. Schools can select two students to take part in the scheme and work with the professional mentors. The projects are chosen by the mentors and encompass a broad range of disciplines.

BHP Science Awards. The BHP awards ${ }^{\ddagger}$ recognise student scientific research in four broad areas, one of which, Physics and Engineering, encompasses astronomy-related research. The scheme is a national competition, although many states also run their own comparable competitions.

\section{An Australian School Example}

Education is primarily the responsibility of the states in Australia; hence each state has its own curriculum and syllabus. The recent overhaul of the Stage 6 Science syllabi (Higher School Certificate or matriculation level subjects) in New South Wales** provided an exciting opportunity to implement a statewide SRP scheme. This was in fact included in the Draft syllabi released in April 1999, but compulsory SRPs were removed from the final syllabi released in July. The removal was primarily due to negative response from teachers. Given that student investigations are now required at each of stages 4 and 5 (Years 7-10) in the new junior Science syllabus that is to be implemented in 2000, had senior SRPs been retained, students would have had an opportunities to develop their research skills throughout their entire career in high school.

\section{Model of SRPs at Blue Mountains Grammar School}

Blue Mountains Grammar School (BMGS) ${ }^{\dagger \dagger}$ is an independent K-12 school located $100 \mathrm{~km}$ west of Sydney in the Blue Mountains. A non-selective school, it has run a program of student research for the last 14 years and is arguably one of the most experienced schools within NSW in running SRPs. All students undertaking one or more science subjects at HSC level (i.e. matriculation standard) are required to undertake a research project over a ten month period. The project counts towards their HSC assessment and is submitted

\footnotetext{
CREST Awards (http://www.csiro.au/communication/csiroedp/crest.htm) CSIRO Student Research Scheme (http://www.csiro.au/)

BHP Science Awards (http://www.bhp.com.au/scienceawards/index.htm)

* NSW Board of Studies (http://www.boardofstudies.nsw.edu.au/)

+ BMGS (http://www.bmgs.nsw.edu.au/)
} 
in three stages. The first submission includes a literature review and initial proposal for the project. Students also have to give a five minute verbal presentation to their peers and respond to questions. One term later, students must submit a detailed method for their work. The final submission, a written report, is due early in Term 3 of their final year, prior to the formal HSC examination that takes place in Term 4.

Students are generally free to select their own topic, although staff also provide suggestions. Generally, students find choosing a topic one of the most difficult aspects of the project. Projects proceed only once a student has discussed their ideas and concept with staff. Over recent years, a number of students have tackled projects in astronomy. These have included:

- Wide-field CCD imaging/differential photometry of AI Velorum, a short period variable star; utilising a $50 \mathrm{~mm}$ lens with a SBIG ST-8 CCD to take images. The differential photometry was performed using the Hands-On Universe (HOU) ${ }^{*}$ software and Excel.

- Determination of open cluster ages and distances. These projects used images obtained either on the 60 -cm telescope at the University of Western Sydney (UWS), Nepean, or on the Remote Access Astronomy Project ${ }^{\dagger}$ telescope at the University of California Santa Barbara (UCSB). Again, image analysis and photometry was performed using HOU and Excel.

- Optical quasar variability; involved imaging of a quasar using the UWS $60 \mathrm{~cm}$ telescope, HOU, Excel and the use of web resources SkyView ${ }^{\ddagger}$ and the NASA Extragalactic Database, $N E D^{* *}$.

- Solar flare radio observations; using a $151 \mathrm{MHz}$ Yagi system provided to BMGS by Taunton Radio Astronomy Observatory plus additional data.

- Visual, photographic and radio meteor observations. There have been several related projects on this theme, including the construction of a hoop antenna to detect meteor showers.

- Analysis of cyclone strengths using satellite images and $H O U$ software. Although not strictly astronomical, it highlights the versatility of image analysis software and further possibilities for projects in remote sensing.

- Analysis of Australia Telescope Compact Array data to study supernovae remnants (SNRs) in the Large Magellanic Cloud (LMC).

- mm-wave observations of the Orion molecular complex using the Mopra radiotelescope, near Coonabarabran in NSW.
Some of these have involved the use of equipment loaned from UWS Nepean. Other projects have relied upon apparatus that the students themselves built or simple equipment such as SLR cameras.

Increasingly, computers play a vital role in data analysis, access to online resources, communication and in presentation of quality reports (Hollow 1998). Students are encouraged to develop spreadsheet and word processing skills and have access to the internet and software tools in the science labs at school. They are also free to consult with staff and submit drafts for appraisal. Students have one teacher allocated as supervisor for their project although this is not necessarily their classroom teacher; it depends upon staff expertise. Many students make contact with professional researchers and are often pleasantly surprised by the support and comments they receive. This is an important aspect of the work.

Two of the astronomy-related projects conducted so far have involved the formal use of a mentor, in each case from UWS Nepean. The first of these, SNRs in the LMC by Bronwyn Wilkes was mentored by Dr Miroslav Filipovic and earned Bronwyn first prize in the BHP Science Award in 1997. The other involved three students studying the Orion molecular complex using the CSIRO ATNF Mopra radiotelescope under the supervision of Maria Hunt from Nepean Observatory. They each selected one or more molecules to observe, performing the analysis independently before swapping results to build up a more complete picture. The impetus for this scheme came from the students themselves and followed on from an earlier observing run the students had participated in at Mopra when in Year 10.

The model of SRPs at BMGS has evolved over time but the school remains committed to the concept. Successful implementation of such a model does require considerable time and enthusiasm by staff. That this is provided annually is a reflection of the value of the scheme as perceived by staff. The school attracts large numbers into its HSC science classes even though students are aware of the additional requirement of an SRP. A significant proportion of students, in some years over $50 \%$, go on to pursue science/technology related further studies or employment. Comments from ex-students suggest that they found the SRP one of the most useful and challenging tasks they accomplished in their school careers and one that placed them well for future challenges and Honours-level study and beyond at university.

Another aspect of student research at BMGS involves a less formal approach through student involvement in extra-curricular Astronomy and Science clubs. One particular group of students was involved in a 
project called ConCat (Constellation Catalogue)* . This involved them using the ST-8 CCD and a high quality $15 \mathrm{~mm}$ lens to obtain wide field images of the constellations and making them available over the web. None of the students had any experience in observational astronomy, CCD imaging or web writing prior to the commencement of the project. All learnt valuable skills as it progressed and worked well as a group both in all night observing sessions and back in the classroom analysing the images. A major benefit of a group project such as this is that it allows individuals to join and move on as circumstances demand, yet also provide a setting in which skills can be acquired and practised. Many of the students involved in this project went on to undertake the more challenging astronomy research projects in Year 12.

\section{International Examples}

There are many innovative and exciting schemes running around the world. Three have been selected and are outlined below.

\section{Hands-On Universe Asteroid Search}

The HOU Asteroid Search was developed by two American teachers, Tim Spuck and Hughes Pack (Spuck 1998), to allow students to study deep images from the CTIO $4 \mathrm{~m}$ class telescope to find asteroids using the $H O U$ software. Students have to work through online tutorials developed by the teachers. Once conversant with the techniques, they work in teams within a school and compare their results with a team from a partner school. The potential of the scheme became evident when students from two of the trial schools discovered a Kuiper Belt Object, 1998 FS144.

Given the wealth of data now available from a number of telescopes around the world, this type of scheme can be adapted to a range of collaborative or group projects. Resources such as the $H O U$ software and curriculum materials have been specifically adapted or written for school students and are versatile and easy to use (Pennypacker \& Asbell-Clarke 1996). The development of a global network of remote access or robotic telescopes for student use will also greatly facilitate the spread of worthwhile research projects.

\section{Taunton Radio Astronomy Observatory}

The Taunton School, in Somerset UK, is home to a dynamic group of student researchers who design, build and use a variety of radiotelescopes to observe the sky. The Taunton Radio Astronomy Observatory (TRAO) ${ }^{\dagger}$ has been developed over ten years by voluntary students working after hours in groups on specific projects. It has evolved from building simple dishes from chicken wire to more complex systems such as a twin $4 \mathrm{~m}$ dish 1420 $\mathrm{MHz}$ interferometer. They were one of the few amateur groups worldwide to obtain useful radio data from the collision of Comet Shoemaker-Levy 9 with Jupiter (Hill 1995). One of their schemes, funded in part by PPARC, has seen them design, construct and distribute $151 \mathrm{MHz}$ Yagi solar radiotelescopes to over 40 schools across Britain and around the world. They will form Solar Watch 2000, monitoring the forthcoming solar maximum and allowing schools to exchange data on solar activity. Other recent projects include AMORA (A Mobile Observatory for Radio Astronomy), which incorporates a 4 metre, fully steerable dish mounted on a custom built vehicle that has its own power supplies and communications equipment. Part of the funding for the project was conditional on it travelling to other schools as a mobile laboratory. Two students from the school designed a $4 \mathrm{~m}$ dish operational to $20 \mathrm{GHz}$ from composite materials. Their design is now used by a local manufacturer to construct dishes for telecommunications. TRAO has also recently been granted space on the University of Surrey Education Satellite for one of their new receivers.

The depth and scope of TRAO's achievements is impressive and derives from both the enthusiasm and effort of the students and their teacher, Trevor Hill. Exstudents have also maintained an interest in the group and provided ongoing support. The observatory is also fortunate in having developed strong links with professional astronomers at the Mullard Radio Astronomy Observatory and the financial backing of a range of corporate and government sources. That they continue to gain this support reflects upon the quality of their work and achievements.

\section{European Association for Astronomy Education Astronomy On-Line}

The European Association for Astronomy Education $(\mathrm{EAAE})^{\ddagger}$ is a regional organisation that seeks to foster greater awareness of science and astronomy through an activities and research-based approach. Its primary method of disseminating ideas and coordinating activities is via the web in its Astronomy On-Line program. Many of its projects require little or no equipment. Rather, the emphasis is on groups of students gathering data through naked-eye or telescopic observations and sharing it with other groups in other countries. Specific events such as lunar and solar eclipses are targeted. The web pages provide background material and links, and facilitate communication and collaboration amongst groups. Given that the target population of schools within Europe is relatively likely to have internet access, this allows distribution costs to be kept low and makes it easy to provide up-to-date information. The concept is

\footnotetext{
* ConCat (http://www.nepean.uws.edu.au/astronomy/concat.html)

† Taunton Radio Astronomy Observatory (http://www.taunton.somerset.sch.uk/trao/)

\$ European Association for Astronomy Education (http://www.eso.org/outreach/spec-prog/aol/)
} 
one that is easily expandable or transferable to other locales.

\section{Key Issues}

In seeking to implement and develop SRPs more widely within schools, a number of key issues need to be considered.

Support. Support is vital and can be discussed with respect to the two major groups involved:

Students. Ultimately, SRPs are only of any value if students find them worthwhile and a positive educational experience. It is important, therefore, that students are provided with the following as a minimum.

- clear guidelines as to what a SRP involves and requires;

- samples of quality projects completed by previous students help in setting the standard;

- a clearly identified contact person, usually a teacher but sometimes a mentor should be available to coordinate the project; and,

- regular monitoring of their progress is necessary. It provides the student with feedback and encouragement and should also serve to identify potential problems and allow them to be solved before they get out of hand.

Teachers. The role of teachers in a successful SRP program is critical. The rejection of the compulsory SRP in the new NSW senior science syllabi was probably largely due to the considerable anxiety and uncertainty by many teachers as to what SRPs involved, how they were to be resourced, how they could be fairly assessed and where teachers would find the time to supervise them. All of these concerns are valid but have been overcome in some schools such as BMGS. Some areas in which support could be provided are outlined below:

- Proper training and professional development of teachers as to expectations and requirements.

- Sabbaticals with professional researchers. Most science teachers probably have little experience of actually undertaking scientific research and hence are more likely to be uncertain about the value and technicalities of research within a school setting. Matching students with academics would be one way of addressing this problem. Others could include incorporating a compulsory research task in undergraduate science degrees or in teacher education courses, although this is likely to help in the long term.

- Communication. Teachers are now more able to communicate with colleagues in other schools and other professionals via e-mail and the like. Effective communication helps teachers raise, discuss and solve problems and feel more positive and active about their roles. Networks of teachers/academics involved in SRPs within disciplines could be established and developed relatively easily online. These would also encourage the sharing of resources and ideas.

Curriculum. The major impediment to the broader implementation of SRPs is their place within a formal syllabus or lack thereof. Most schools will only undertake SRPs if they are a syllabus requirement. The recent failure to adopt the model in NSW at the senior level is discouraging, but may only prove temporary. As students move through Years 7-10 (Stages 4 \& 5) having to undertake two compulsory investigations they become better placed to consolidate their skills through a senior SRP. Teachers are also likely to become more familiar and comfortable with the concept, and perhaps more open to change in the future. The paucity of quantitative research may currently hinder those supporting the adoption of an SRP model, but the anecdotal evidence is still most encouraging (Lockwood 1992; Gott \& Duggan 1995).

Funding. At present there is no formal source of funding for general SRPs in NSW or Australia. Specific programs such as Streamwatch are funded in part by relevant government agencies. Environmental programs are perhaps better supported than other areas, but there are no known sources for research in the physical sciences. Schools such as Taunton have shown what can be achieved through appropriate funding. Institutions such as the Royal Society have a scheme allowing schools to apply for grants for specific projects. A similar scheme, if instituted in Australia, would be invaluable in helping schools acquire basic or specialised equipment or develop materials for others to use. Start-up funding can be a useful catalyst for schools or groups of educators and provide motivation to both students and teachers.

The provision of some funding within the National Science Foundation grants in the US for researchers to link up with educators is another concept worth exploring. Although research funding is very tight in Australia, it is ultimately in researchers' interest to have a public who appreciate what research is and its value to society. A relatively small percentage of funds allocated to educational links may provide many benefits to all parties involved.

Time. The key issue with time is to acknowledge that there is never enough of it! With this in mind, it is reasonable and sensible to institute procedures that are efficient and productive. SRPs can be a very positive and worthwhile educational experience, but they are time consuming. Any school seeking to implement them must acknowledge this fact and allow adequate time for them. Of equal importance is the need for groups running SRPs to share ideas and resources and not reinvent wheels. Many of these concerns can be avoided through communication, but some will involve the establishment of effective mechanisms and support groups. 
Sharing Results. Students have much to benefit from the sharing of their work. Several opportunities already exist for students to submit or publish their work and others could be established. These include:

- Competitions such as the BHP Science Awards and the international First Steps Towards a Nobel Prize in Physics provide an external measure of the student's work. The winners in the First Step competition also have their work published in a journal (Gorzkowski 1999).

- Publication of student work in an appropriate journal (Percy \& Rincón 1996) is a great motivator for students and a worthy aim for those who produce high standard work.

- Web-based research journals provide an efficient and convenient method of publishing student research work. Two journals are already established to publish student work; The Empiricist* and The Sci-I Journal $l^{\dagger}$ actively encourage and publish student work. This concept could be readily extended and operate at a variety of levels.

- Student conferences or workshops provide another opportunity for students to discuss and present their work. One such scheme already operates at the University of Toronto as the endpoint of their Student Mentor scheme. If SRPs become more widespread in an Australian setting, thought should be given to providing students with access to appropriate forums such as workshops or seminars.

Fostering Collaborations. For the full potential of SRPs to be realised, strong links between students, teachers and researchers are essential. Teachers need to be encouraged to be open to change and prepared to experiment. Researchers should be encouraged to consider what educational opportunities can flow from their work and to link up with interested educators. Funding agencies and educational bodies can both be active in this regard, instituting policies that positively discriminate in favour of researcher/educational collaborations.

\section{The Future}

There are many opportunities to extend the range and spread of SRPs in schools. Several things can be done to support this:
- More research into what works and what does not is required. The experience already obtained from schools in a variety of settings needs to be collated and evaluated and key points identified.

- The existing current schemes in schools should be supported and extended.

- New ideas for schemes need to be encouraged and trialed.

- The value of SRPs as an integral and important component of a balanced education in Science should be established.

- The passion that exists within current proponents of the scheme needs to be maintained and allowed to spread.

Astronomy is a discipline that lends itself to collaborations at both the research and the education level. Simple research projects that can achieve worthwhile results through collaborations include:

- Variable star monitoring

- Meteor shower observations

- Surveys of light pollution

All of these require minimal equipment and could relatively easily be implemented in schools across Australia.

\section{References}

Gorzkowski, W. 1999, First Step to Nobel Prize In Physics (Warsaw: Instytut Fizyki PAN)

Gott, R., \& Duggan, S. 1995, Investigative Work in the Science Curriculum (Open University Press)

Hill, T. 1995, Phys. Education, 30, 135

Hollow, R. 1998, in Astronomical Education with the Internet, Frontiers of Science series no. 27, ed. M.Okyudo et al. (Tokyo: Universal Academic Press), p. 21

Lockwood, J. F. 1992, Hands-on Astronomy for Education (Singapore: World Scientific), p. 43

Pennypacker, C., \& Asbell-Clarke, J. 1996, in Astronomy Education: Current Developments, Future Coordination, ASP Conf. Series, vol. 89, ed. J. Percy (San Francisco: ASP), p. 61

Percy, J. R., \& Rincón, A. M. 1996, J. Am. Assoc. Variable Star Observers, 24

Spuck, T. 1998, in Astronomical Education with the Internet, Frontiers of Science series no. 27, ed. M.Okyudo et al. (Tokyo: Universal Academic Press), p. 73 